\title{
$n^{\circ} 2020-12$
}

\section{Reaching New Lows? The Pandemic's Consequences for Electricity Markets}

\section{David BENATIA ${ }^{1}$}




\title{
Reaching New Lows? The Pandemic's Consequences for Electricity Markets
}

\author{
David Benatia*
}

June 5, 2020

\begin{abstract}
The large reductions in electricity demand caused by the COVID-19 crisis have disrupted electricity systems worldwide. This article draws insights from New York into the consequences of the pandemic for electricity markets. It disentangles the effects of the demand reductions, increased forecast errors, and fuel price drops on the day-ahead and real-time markets. From March 16 to May 31, New York has experienced a 6.5\% demand reduction, prices have dropped, and producers have lost $\$ 87$ million (-18\%). This estimate extrapolates to $\$ 2.6$ billion for the entire US. Looking forward, these new lows signal the needs for market design adjustments.
\end{abstract}

Keywords: COVID-19, Demand, Energy, Electricity Markets JEL Codes: L94, Q02, Q41, Q47

${ }^{*}$ CREST (UMR 9194), ENSAE, Institut Polytechnique de Paris, 5 Avenue Henry Le Chatelier, 91120 Palaiseau, France (e-mail: david.benatia@ensae.fr). This research is supported by grants of the French National Research Agency (ANR), "Investissements d'Avenir" (LabEx Ecodec/ANR-11LABX-0047) and "Instrument de financement : Projet de Recherche Collaborative - Entreprise" (ANR EcoREES). The author acknowledges financial support from Groupe des Écoles Nationales d'Économie et Statistique (GENES) and Laboratoire de Finance des Marchés de l'Énergie (FIME). The author thanks Clémence Alasseur, Natalia Fabra, Pierre-Olivier Pineau, Peter Tankov, Matthew White, Florian Ziel and participants to the FIME seminar for their helpful comments. 


\section{Introduction}

Under the "Great Lockdown", demand for energy is plunging in the worst economic downturn since the Great Depression (IMF, 2020). As a large share of economic activities are on pause, many electricity systems experience unusual patterns of consumption and coincidentally low wholesale prices. Lockdown measures caused unprecedented reductions of electricity demand ranging from 3-4\% in Texas (ERCOT, 2020) up to 20-25\% in Italy (Narajewski and Ziel, 2020). Those large sudden variations are unparalleled in history, even during major economic crises (RTE, 2020).

This paper proposes a method to quantify the impacts of the COVID-19 crisis on electricity markets and discusses its possible long-term consequences. The empirical analysis is centered around the New York electricity market, which is at the epicenter of the crisis in the United States. The methodology directly applies to any electricity market.

Wholesale electricity prices have been trending downward over the past decade. The electricity use by U.S. households has been slowly decreasing since 2012 (Davis, 2017). At the same time, natural gas prices have declined and renewable energy penetration has largely increased. Wind power production has more than doubled to reach above $7 \%$ of total domestic electricity generation in 2019 (EIA, 2019). ${ }^{1}$ Although energy efficiency improvements, renewable energy deployment, and low energy prices are desirable, they result in low profitability for investments in electrical generation by depressing wholesale market prices (Ambec and Crampes, 2012). Economists acknowledge the needs to address this issue in order to reach large penetration rates of renewables (Newbery et al., 2018).

The evolution of electricity demand and wholesale prices in New York is shown in Figure 1. In early 2020, statewide demand and prices were already low compared to previous years. In an effort to contain the virus outbreak, schools closed in NYC on March 16, 2020. On March 22, 2016, the statewide stay-at-home order became effective. Those containment policies have set new record lows in NY electricity markets. This observation largely extends to many electricity systems. The long-term consequences of the pandemic will depend on the frequency of those new lows. Unfor-

\footnotetext{
${ }^{1}$ For comparison, the share of wind power is about $15 \%$ in Europe.
} 
tunately, epidemiologists predict that the virus is here for a long time and that a single round of "social distancing" will not be sufficient in the long term (Kissler et al., 2020; Moore et al., 2020). In any case, those new lows must primarily act as a warning signal about the needs for an economically efficient and sustainable energy system design if ambitious renewable objectives are to be met.

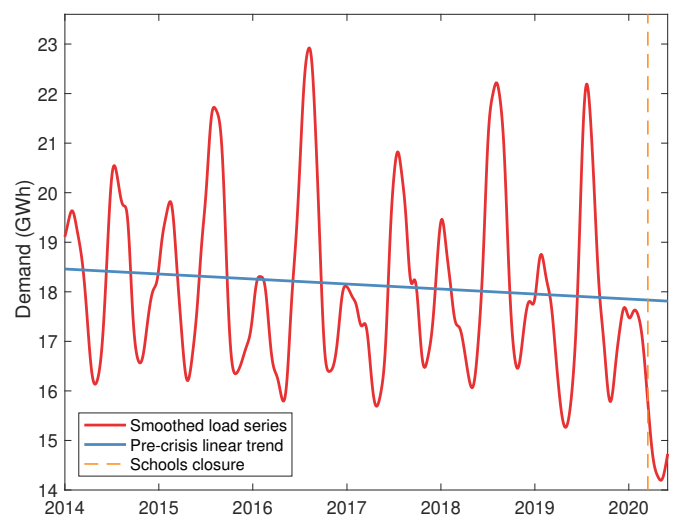

(a) Electricity demand (2014-2020)

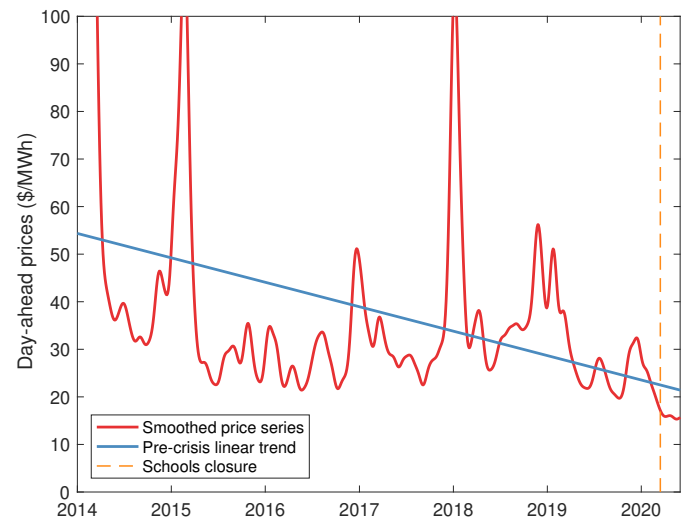

(b) Day-ahead electricity prices (2014-2020)

Figure 1: Demand and prices in New York (2013-2020)

Contributions and main results. This paper has three main contributions. First, we develop a methodology to evaluate the impacts of containment measures on electricity demand and forecast errors using a machine-learning approach. Second, we propose an empirical framework to disentangle the respective short-term effects of demand reductions, increased forecast errors, and fuel price drops on wholesale prices in the day-ahead and real-time markets. The estimates are then used to assess losses in revenues for market participants. We conclude the paper by discussing required short-run adjustments and the potential long-run consequences of the pandemic.

New York is found to have experienced on average a $6.5 \%$ electricity demand reduction since the beginning of containment measures on March 16, 2020 to May 31, 2020. New York City (NYC) is the most affected area with a $12 \%$ reduction. Daytime consumption has decreased by $17 \%$ in NYC during weekdays and daily consumption patterns have considerably changed. Those results are in line with EIA (2020) and NYISO (2020), and are qualitatively similar to electricity markets in North America (AESO, 2020; Brewer, 2020; ERCOT, 2020; ISONE, 2020; PJM, 2020) and Europe 
(Narajewski and Ziel, 2020; RTE, 2020).

Findings reveal that short-term load forecasting in New York failed to quickly adjust to the structural break caused by containment measures. Load forecast errors have surged (by up to 300\%) and over-forecasting has been persistent during the first four weeks of the lockdown. Around the globe, system operators have mobilized their workforce to attenuate forecast errors (NYISO, 2020; RTE, 2020; Narajewski and Ziel, 2020) in an effort to mitigate its economic consequences. Large forecast errors result in inefficient daily system operations because of additional operating costs from unnecessary start-ups and provisions of spinning reserves (Ortega-Vazquez and Kirschen, 2006).

During the lockdown, wholesale prices have dropped by $15 \%$ in the day-ahead (DA) market and $23 \%$ in the real-time (RT) market, on average. The reductions in DA prices are attributed to demand reductions from the lockdown (40\%) and low fuel prices $(60 \%)$. We also find that DA price reductions have been partly mitigated by the planned retirement of a nuclear power plant during the same period. DA prices would have dropped further down had the plant not retired. On the other hand, RT prices were mainly affected by increased forecast errors (35\%), low fuel prices (34\%) and low demand $(31 \%){ }^{2}$

As a consequence of reduced demand and prices, the DA market value has depreciated by $\$ 90$ million in 11 weeks $(-18.5 \%)$. At the same time, the RT market value has appreciated by $\$ 3.7$ million ( $+28 \%$ ) because enlarged forecast errors have resulted in larger traded volumes in real-time. The total effect on the NY electricity market value is estimated at $\$ 87$ million (-18\%), where baseload suppliers might have been the main losers. This estimate extrapolates to the total US electricity industry at $\$ 2.6$ billion in lost revenues for electricity suppliers. ${ }^{3}$ This value is at best a rough estimate because electricity systems have different energy mix and have experienced different demand reductions. Nevertheless, it indicates that revenue losses are large, but not as large as for some other economic sectors, or countries. For instance, the International Air Transport Association predicts a $\$ 50$ billion (-27\%) fall of revenues for airlines in

\footnotetext{
${ }^{2}$ The effects on transmission constraints (and congestion contracts) and prices for ancillary services are beyond the scope of this paper.

${ }^{3}$ Total electricity generation in the US was 30.5 times larger than in NY during April 2019 (EIA, 2019). This estimate only accounts for the effect of low fuel prices and lockdown measures.
} 
North America for 2020 (IATA, 2020).

Literature. This paper is related to three strands of the literature. First, the paper is the first to evaluate the lost revenues caused by the pandemic in electricity markets. Several papers study the impacts of the COVID-19 pandemic on energy markets. Ftiti, Ben Ameur and Louhichi (2020) review the dynamics of the oil markets during the pandemic and discuss the prospects for the industry moving forward. Benatia (2020), Narajewski and Ziel (2020) and Percy and Mountain (2020) study the electricity demand reductions caused by social distancing restrictions in New York, continental Europe, as well as Australia, New Zealand and Great Britain. Finally Tsagkari (2020) argues that the pandemic will radically change the energy sector as demand shrinks and the digitization of the economy develops further.

Second, the empirical framework developed in this paper follows a similar approach than Benatia and Billette de Villemeur (2019) and Burlig et al. (2019), among others, where a machine learning approach is used to estimate counterfactual outcomes in a micro-economic context. The neural network model developed in this paper is easy to implement in other electricity markets. Similar methods have been used by system operators (AESO, 2020; ERCOT, 2020; PJM, 2020; NYISO, 2020; RTE, 2020) to evaluate the demand reductions caused by containment measures. This paper contributes to this empirical literature by outlining the underlying assumptions necessary for these methods to deliver estimates with a causal interpretation.

Third, the empirical specification used to estimate aggregate supply curves in the DA and RT markets is based on economic theory. We use the approach in Wolfram (1999) and specify a sequential market model in line with Ito and Reguant (2016).

The remaining of the paper is organized as follows. The effects of lockdown on demand and forecast errors are quantified in Section 2. The short-term impacts on DA and RT markets are investigated in Section 3. Section 4 discusses short- and long-term consequences. Section 5 concludes the paper. 


\section{Electricity demand under lockdown}

The New York electricity system operator (NYISO) is the legal entity in charge of system operations and grid reliability. The system is divided into 11 interconnected load zones, as depicted in Figure 2. Due to the frequent occurrences of transmission limitations within the state, NYISO has opted for a nodal pricing market design. In simple terms, it means that prices differ across the state depending on the spatial distribution of demand and current operational constraints. In this paper, we avoid having to deal with the $500+$ nodal prices by focusing on the 11 zonal prices, which are load-weighted averages of nodal prices.

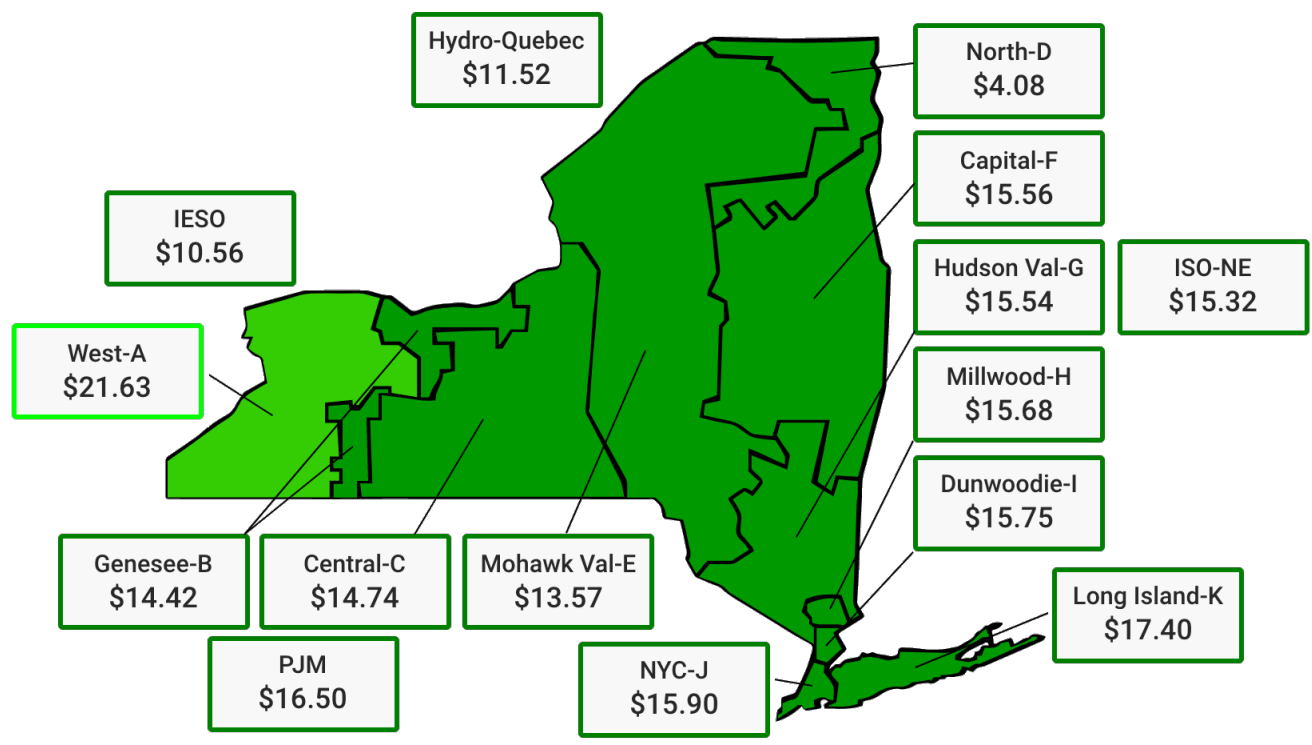

Figure 2: Electricity demand zones in the New York State (prices from 2020/05/11)

The wholesale market is organized as a sequential multi-unit auction where retailers buy wholesale energy from electricity suppliers. The DA market takes place one day prior to physical production and is used to allocate resources efficiently based on demand forecasts for the following day. It amounts to $95 \%$ of total energy exchanges. The remaining 5\% takes place in the sequential RT market during the day of actual production. This market is essentially used as a balancing mechanism to adjust for forecast errors and supply contingencies. ${ }^{4}$

\footnotetext{
${ }^{4}$ The interested reader is referred to Benatia (2018) for a detailed presentation and analysis of the
} 
In 2019, 39\% of in-state electricity generation came from fossil fuel generators (natural gas and dual-fuel), 34\% from nuclear power plants, $22 \%$ from hydro plants, $3.4 \%$ from wind farms and the remaining $1.6 \%$ from solar plants and other renewables. Nuclear and fossil fuel plants are concentrated downstate, whereas hydro and wind plants are mainly located upstate. In addition to in-state production, New York exchange electricity with interconnected regions: Ontario (IESO), Québec (Hydro-Quebec), New England (ISO-NE) and Pennsylvania, New Jersey, and Maryland (PJM).

\subsection{Load forecasting and causal inference}

The New York electricity system operator (NYISO) uses a combination of advanced neural network and regression type models for load forecasting (NYISO, 2019). This algorithm feeds on weather forecasts and recent load realizations to predict hourly electricity demand in each of the 11 load zones for the following days. The algorithm proves to be reliable with a mean relative absolute error for day-ahead forecasts below $2 \%$ over the period 2014-2020.

Counterfactual demand. Our modelling approach consists in training a neural network capable of predicting the hourly load for each zone under business-as-usual conditions, but without relying on the most recent load realizations or other endogenous variables possibly affected by containment measures. The objective is to construct a reliable counterfactual electricity demand assuming containment measures had not been enacted for the entire lockdown period. This is not a forecasting exercise. The discrepancies between the model's predictions and the actual realizations have a causal interpretation as the effect of containment measures on electricity consumption. The advantage of this method is to be able to credibly perform causal inference and obtain standard errors for the mean effects of interest. The counterfactual hourly demand will then be used to evaluate market impacts in Section 3.

The identification of causal estimates relies on two assumptions: 1) demand is perfectly price-inelastic and 2) the treatment selection conditionally on covariates is as good as random. The first assumption is standard about electricity markets. The sec-

New York electricity market. 
ond condition holds as long as, conditional on the predictors, there is no omitted factor correlated with both the timing of containment measures and variations in electricity demand. In the context of this paper, this condition would fail if, for instance, an unobserved economic downturn was not a consequence of the enactment of lockdown measures but only coincidental.

The model, hereafter denoted NNet, has a set of 317 predictors, all exogenous to lockdown measures. This set includes: ${ }^{5}$

- 171 hourly weather variables: temperature, dew point temperature, humidity, wind speed, wind angle, wind gust, pressure, precipitations and a categorical variable representing weather conditions (e.g. cloudy, snow, thunder, etc.) collected from 19 weather stations nearby airports in New York state;

- 68 daily weather variables: daily max and min temperatures, daily max and min wet bulb temperatures collected from 17 weather stations nearby airports in New York state;

- 12 eighty-days lagged hourly load realizations: hourly load realizations from 2.5months ago capture some time dynamics and were realized before the lockdown, even for May 31.;

- 61 time variables: fixed-effects for hour of the day, day of the week, and month of the year, holidays and a linear time trend.

The algorithm has a single-hidden layer with 5 neurons. ${ }^{6}$ It is separately trained for each zone by minimizing the Mean-Squared-Errors (MSE) criterion using a randomly selected training sample with $70 \%$ of the 34,949 hourly observations for the months of October to May during 2014-2020 prior to school closures in NYC on March 16, 2020. The remaining observations are randomly split into a validation (20\%) and testing $(10 \%)$ datasets. $^{7}$ The algorithm is then used to predict demand for 1870 hours between March 16 and May 31, 2020.

\footnotetext{
${ }^{5}$ The hourly weather data was retrieved from https://www.wunderground.com. The daily weather data is used in NYISO forecasting algorithm and can be obtained from https://www.nyiso.com.

${ }^{6}$ More specifically, the algorithm is a two-layer feed-forward network with 5 sigmoid hidden neurons. The network is trained with Levenberg-Marquardt backpropagation algorithm in MATLAB.

${ }^{7}$ More specifically, each day is randomly attributed to a set (training, validation, or testing), including all 24 hours in order to prevent overfitting.
} 
Table 1 shows means and standard deviations (in parentheses) for the main variables of interest: realized load (in GWh), forecast errors in absolute terms (in MWh), DA and RT prices (in \$/MWh), for the 40,228 observations across the 11 zones in New York, and the total for New York (NYISO). Forecast errors are computed as the difference between load forecast and realized load, including losses. ${ }^{8}$ Prices for NYISO are calculated as load-weighted zonal prices.

Table 1: Summary statistics

\begin{tabular}{lcccccccc}
\hline \hline & \multicolumn{2}{c}{ Actual load } & \multicolumn{2}{c}{ Abs. Forecast error } & \multicolumn{2}{c}{ DA price } & \multicolumn{2}{c}{ RT price } \\
\hline Capital & 1.33 & $(0.20)$ & 57.78 & $(41.90)$ & 39.84 & $(41.27)$ & 38.55 & $(47.36)$ \\
Central & 1.83 & $(0.27)$ & 95.09 & $(57.14)$ & 29.48 & $(30.60)$ & 29.23 & $(37.42)$ \\
Dunwood. & 0.64 & $(0.11)$ & 23.67 & $(22.47)$ & 38.62 & $(38.56)$ & 37.25 & $(44.70)$ \\
Geness. & 1.09 & $(0.16)$ & 44.35 & $(32.24)$ & 28.15 & $(29.23)$ & 27.82 & $(35.55)$ \\
Hudson V. & 1.05 & $(0.17)$ & 50.29 & $(39.19)$ & 25.72 & $(31.07)$ & 24.63 & $(41.18)$ \\
Long Isl. & 2.16 & $(0.37)$ & 65.10 & $(64.65)$ & 38.23 & $(38.43)$ & 36.97 & $(44.38)$ \\
Mohawk V. & 0.90 & $(0.17)$ & 137.21 & $(48.42)$ & 45.34 & $(42.68)$ & 44.18 & $(53.76)$ \\
Milwood & 0.31 & $(0.06)$ & 21.80 & $(19.51)$ & 29.97 & $(32.28)$ & 29.69 & $(38.90)$ \\
NYC & 5.52 & $(0.88)$ & 112.91 & $(110.63)$ & 38.57 & $(38.69)$ & 37.25 & $(44.67)$ \\
North & 0.55 & $(0.09)$ & 19.26 & $(16.07)$ & 39.86 & $(40.51)$ & 38.85 & $(47.21)$ \\
West & 1.74 & $(0.21)$ & 60.60 & $(43.67)$ & 25.06 & $(31.00)$ & 24.82 & $(41.92)$ \\
NYISO & 17.11 & $(2.51)$ & 534.98 & $(365.97)$ & 35.08 & $(35.55)$ & 34.77 & $(41.12)$ \\
\hline
\end{tabular}

Notes: This table shows means and standard deviations (in parentheses) for realized load (in GWh), forecast errors in absolute terms (in MWh), DA and RT prices (in $\$ / M W h$ ), for the 36,819 observations across the 11 zones in New York, and the total for NYISO (last row).

Performance and lockdown measures. The predictive performance of NNet fairs well with respect to that of NYISO's algorithm, hereafter denoted NAlg. Table 2 reports the performance of NNet and the day-ahead forecasts used by NYISO to predict hourly electricity consumption for the test set (3480 observations) and the first three weeks of containment measures. Performance is reported using the mean absolute (relative) prediction errors (MAPE). ${ }^{9}$ For the test set, the MAPEs for statewide demand

\footnotetext{
${ }^{8}$ NYISO load forecasts do not include losses, which create a systematic bias and can be misleading about forecast performances. We correct this bias by taking the average loss factor for each zone in the entire 2013-2020 period.

${ }^{9}$ Note that the MSE is used to train the algorithm. We believe the MAPE to provide more intuitions. This criterion is calculated as $M A P E=\frac{1}{T} \sum_{t=1}^{T} \frac{\left|\widehat{\operatorname{Load}}_{t}-\operatorname{Load}_{t}\right|}{\operatorname{Load}_{t}}$. The interested reader is
} 
(last row) and NYC are around $2 \%$ for both algorithms. MSEs are also for both. There are two main differences between NNet and NAlg. First, NNet uses actual weather conditions rather than weather forecasts and includes many more weather variables. Second, NNet only uses two-months lagged load realizations whereas NAlg uses dayahead observations.

Table 2: Predictive performance

\begin{tabular}{lcccccccc}
\hline \hline & \multicolumn{2}{c}{ Test set } & \multicolumn{2}{c}{ Week 1 } & \multicolumn{2}{c}{ Week 2 } & \multicolumn{2}{c}{ Week 3 } \\
\hline & NNet & NAlg & NNet & NAlg & NNet & NAlg & NNet & NAlg \\
Capital & $3.28 \%$ & $3.17 \%$ & $6.08 \%$ & $3.74 \%$ & $5.67 \%$ & $5.66 \%$ & $4.95 \%$ & $5.82 \%$ \\
Central & $2.52 \%$ & $2.55 \%$ & $5.77 \%$ & $4.99 \%$ & $9.02 \%$ & $7.65 \%$ & $6.42 \%$ & $5.94 \%$ \\
Dunwood. & $3.49 \%$ & $3.24 \%$ & $3.41 \%$ & $2.39 \%$ & $5.32 \%$ & $4.32 \%$ & $5.02 \%$ & $4.25 \%$ \\
Geness. & $2.55 \%$ & $2.42 \%$ & $4.75 \%$ & $3.53 \%$ & $6.74 \%$ & $5.48 \%$ & $5.94 \%$ & $4.94 \%$ \\
Hudson V. & $5.04 \%$ & $3.14 \%$ & $7.44 \%$ & $3.74 \%$ & $6.37 \%$ & $7.01 \%$ & $6.90 \%$ & $6.17 \%$ \\
Long Isl. & $4.33 \%$ & $2.73 \%$ & $5.04 \%$ & $3.31 \%$ & $5.74 \%$ & $6.06 \%$ & $6.36 \%$ & $3.97 \%$ \\
Mohawk V. & $4.14 \%$ & $4.00 \%$ & $7.20 \%$ & $5.94 \%$ & $7.71 \%$ & $5.39 \%$ & $5.83 \%$ & $4.02 \%$ \\
Milwood & $6.52 \%$ & $6.51 \%$ & $4.86 \%$ & $5.41 \%$ & $6.34 \%$ & $6.60 \%$ & $6.50 \%$ & $5.83 \%$ \\
NYC & $2.05 \%$ & $1.93 \%$ & $7.23 \%$ & $4.79 \%$ & $11.44 \%$ & $6.03 \%$ & $13.70 \%$ & $6.61 \%$ \\
North & $3.31 \%$ & $4.24 \%$ & $4.70 \%$ & $3.46 \%$ & $3.93 \%$ & $3.31 \%$ & $3.38 \%$ & $3.58 \%$ \\
West & $2.82 \%$ & $2.38 \%$ & $5.66 \%$ & $2.30 \%$ & $9.75 \%$ & $4.34 \%$ & $7.53 \%$ & $3.35 \%$ \\
NYISO & $2.08 \%$ & $1.75 \%$ & $5.18 \%$ & $3.13 \%$ & $7.32 \%$ & $4.81 \%$ & $7.21 \%$ & $4.12 \%$ \\
\hline
\end{tabular}

Notes: This table shows the performance of our model (NNet) and the day-ahead forecasts used by NYISO (NAlg) to predict hourly electricity consumption for the test set (145 full days, hence 3480 hourly observations) and the first three weeks of containment measures. Performance is measured using the mean absolute prediction errors (MAPE).

The prediction errors of both algorithms are substantially larger during containment measures. For instance, in NYC, the MAPE is around $2 \%$ for both algorithms in the test set. Under lockdown, errors for NAlg increased up to $6.61 \%$ and up to $13.70 \%$ for NNet. We interpret this difference as a consequence of NYISO's forecasting algorithm's ability to adjust using recent load realizations.

referred to Franses (2016) for a discussion of criteria for forecasting performance evaluation. 


\subsection{Demand reductions and forecast errors}

Figures $3 \mathrm{a}$ and $3 \mathrm{~b}$ illustrate the above results. Figure $3 \mathrm{a}$ shows 24 -hours moving averages of the actual NY total load, the NYISO forecast and the NNet counterfactual load from end of February to early May. Both the NYISO forecast and NNet prediction exhibit systematic deviations from the realized load after the enactment of containment measures. Figure 3b zooms in on the first week of lockdown (03/23-03/29). The discrepancy between realized load and its counterfactual predicted using NNet identifies a sizeable effect of lockdown measures during the entire week.

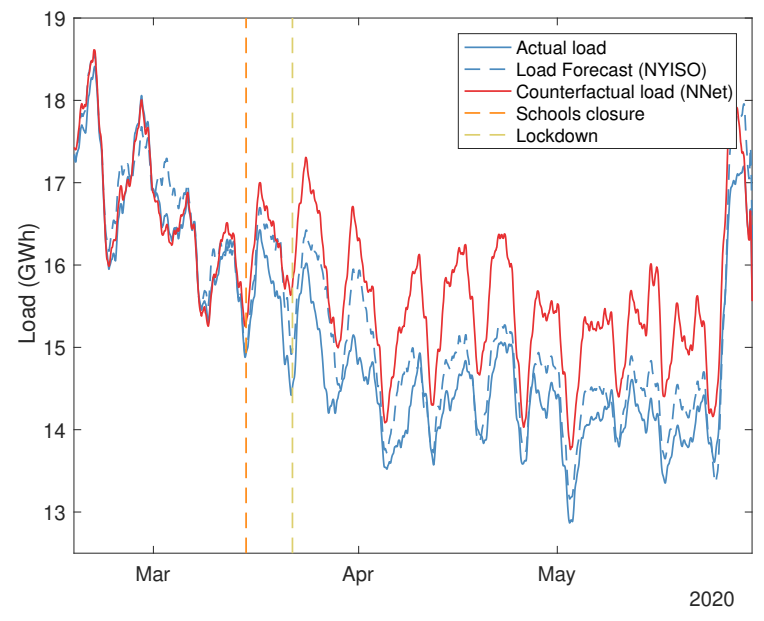

(a) $02 / 18-05 / 31$

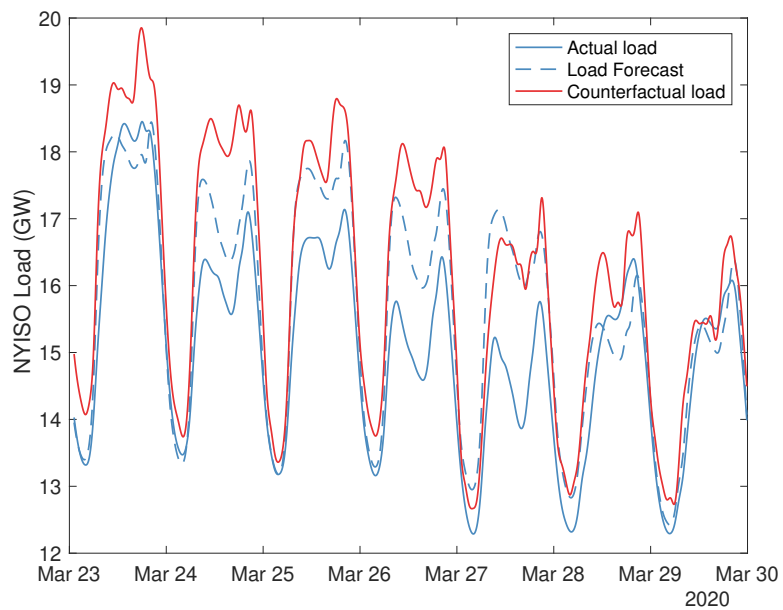

(b) $03 / 23-03 / 29$

Figure 3: Actual load and predictions

Forecast errors. The substantial increase of forecast errors caused by containment measures is reminiscent of Lucas' critique. Although required for the efficient planning of operations, forecasts based on historical realizations may perform poorly following structural changes. Figure 4 shows a 18-hours moving average of the MAPE and its average over 2013-2020. The algorithm appears to have adapted relatively well in about four weeks after the enactment of schools closure in New York. In the meantime, the forecast errors remain consistently above their long-term average. 


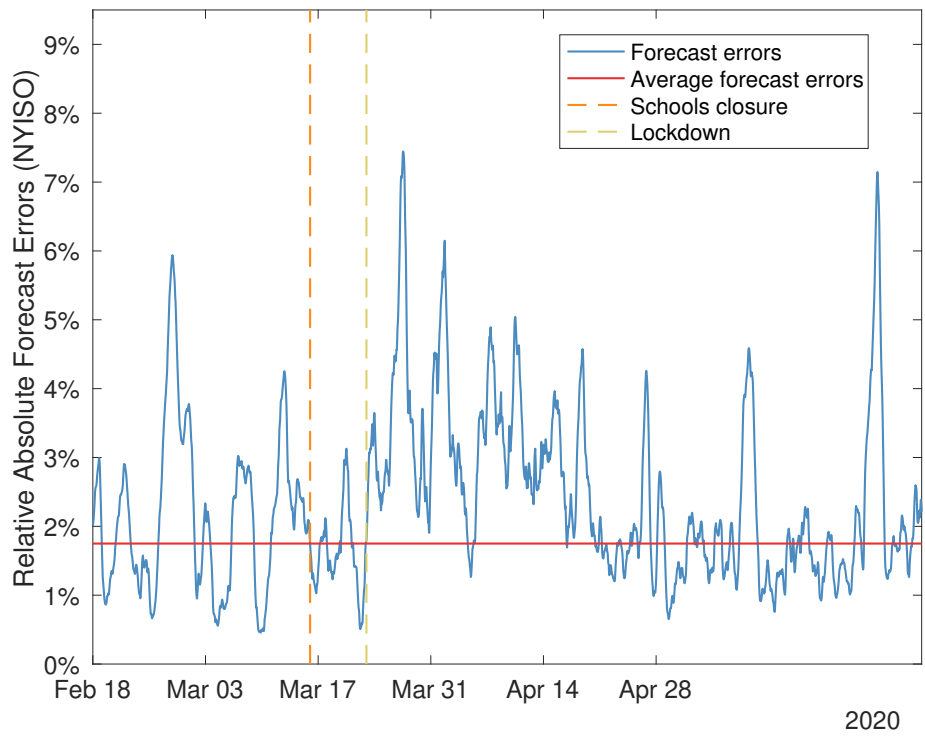

Figure 4: Relative Absolute Forecast errors (NAlg)

Weekly consumption reductions. Weekly demand reductions are estimated as the aggregated differences between actual demand and its counterfactual in the absence of containment measures over the course of each week. Table 3 reports the estimated weekly demand reductions (in GWh) separately for each zone during the week of schools closure and the following six weeks. The load reduction during the week preceding any official measure is estimated at $1.1 \%$ for the entire state $(-29 \mathrm{GWh})$. The purpose of schools closure was essentially to induce parents to stay home. It has resulted in a 6\% (-61 GWh) decrease in NYC and 5\% (-134 GWh) statewide. Finally, electricity demand under lockdown was 10-13\% smaller than usual in NYC and 7-8\% smaller statewide during the first seven weeks of containment. This finding may be explained by some New Yorkers having left to less inhabited areas, and the shutdown of public transit. 
Table 3: Weekly demand reductions (GWh)

\begin{tabular}{lcccccccc}
\hline \hline & $03 / 16$ & $03 / 23$ & $03 / 30$ & $04 / 06$ & $04 / 13$ & $04 / 20$ & $04 / 27$ & \\
\hline & Week 1 & Week2 & Week3 & Week4 & Week5 & Week6 & Week7 & SE \\
Capital & -11.5 & -10.2 & -8.5 & -7.5 & -16.5 & -10.1 & -13.3 & $(2.4)$ \\
Central & -15.5 & -23.9 & -16.8 & -20.9 & -25.3 & -19.3 & -19.5 & $(2.8)$ \\
Dunwood. & -2.4 & -4.4 & -3.3 & -8.0 & -5.1 & -3.9 & -5.2 & $(1.6)$ \\
Geness. & -7.7 & -10.0 & -8.8 & -9.3 & -11.9 & -10.0 & -4.2 & $(1.6)$ \\
Hudson V. & -8.8 & -5.0 & -9.9 & -9.1 & -9.8 & -3.9 & -11.3 & $(3.7)$ \\
Long Isl. & -10.1 & -10.8 & -12.5 & -13.9 & -13.1 & -8.4 & -14.1 & $(5.4)$ \\
Mohawk V. & -8.9 & -10.2 & -5.7 & 1.9 & -1.5 & 3.1 & -1.8 & $(2.2)$ \\
Milwood & 0.2 & 1.6 & -2.3 & -4.1 & -4.5 & -2.6 & -1.1 & $(1.4)$ \\
NYC & -61.5 & -93.4 & -107.3 & -109.2 & -107.2 & -102.6 & -97.9 & $(7.7)$ \\
North & -3.1 & -3.3 & 0.9 & 0.9 & -1.1 & 0.2 & 1.5 & $(1.3)$ \\
West & -13.8 & -24.7 & -19.0 & -17.3 & -20.9 & -18.1 & -22.8 & $(3.2)$ \\
NYISO & -134.1 & -187.0 & -177.1 & -187.8 & -204.9 & -168.9 & -173.3 & $(20.1)$ \\
\hline
\end{tabular}

Notes: This table shows. Standard errors are reported in parentheses in the right-most column.

New daily load patterns All regions under lockdown exhibit new daily load patterns. Table 4 reports the average estimates from 03/23 to 05/04 in New York. Each estimate is the average relative change in electricity demand during night hours (10 $\mathrm{pm}$ to $6 \mathrm{am}$ ), morning hours ( $6 \mathrm{am}$ to $12 \mathrm{pm}$ ), afternoon hours (12 pm to $6 \mathrm{pm}$ ) and evening hours (6pm to $10 \mathrm{pm})$. Standard errors are reported in parentheses. The main finding is an attenuation of morning and afternoon consumption, down by $17 \%$ in NYC and $10-11 \%$ statewide. The morning reduction is found to be statistically significant in nearly all zones. Reductions during other hours are relatively smaller. 
Table 4: Average daily load reductions (weekdays)

\begin{tabular}{lcccccccc}
\hline \hline & \multicolumn{2}{c}{ Night } & \multicolumn{2}{c}{ Morning } & \multicolumn{3}{c}{ Afternoon } & \multicolumn{2}{c}{ Evening } \\
\hline Capital & $-3.9 \%$ & $(1.4)$ & $-7.4 \%$ & $(1.4)$ & $-6.2 \%$ & $(1.6)$ & $-4.9 \%$ & $(1.5)$ \\
Central & $-6.7 \%$ & $(1.1)$ & $-9.7 \%$ & $(1.1)$ & $-8.4 \%$ & $(1.2)$ & $-8.1 \%$ & $(1.2)$ \\
Dunwood. & $0.0 \%$ & $(1.8)$ & $-9.8 \%$ & $(1.8)$ & $-7.5 \%$ & $(2.1)$ & $-6.5 \%$ & $(1.9)$ \\
Geness. & $-2.6 \%$ & $(1.0)$ & $-9.3 \%$ & $(1.1)$ & $-8.6 \%$ & $(1.3)$ & $-7.3 \%$ & $(1.2)$ \\
Hudson V. & $-3.1 \%$ & $(2.4)$ & $-6.3 \%$ & $(2.6)$ & $-7.3 \%$ & $(3.2)$ & $-4.0 \%$ & $(2.7)$ \\
Long Isl. & $-0.3 \%$ & $(2.0)$ & $-6.5 \%$ & $(2.0)$ & $-6.4 \%$ & $(2.8)$ & $-4.0 \%$ & $(2.1)$ \\
Mohawk V. & $-0.3 \%$ & $(2.1)$ & $-2.1 \%$ & $(2.0)$ & $-3.8 \%$ & $(1.9)$ & $-1.9 \%$ & $(1.8)$ \\
Milwood & $-3.1 \%$ & $(3.7)$ & $-7.0 \%$ & $(3.0)$ & $-2.4 \%$ & $(3.3)$ & $-6.2 \%$ & $(2.9)$ \\
NYC & $-5.6 \%$ & $(0.9)$ & $-17.3 \%$ & $(0.9)$ & $-17.7 \%$ & $(0.9)$ & $-14.1 \%$ & $(1.0)$ \\
North & $-0.2 \%$ & $(1.5)$ & $-0.0 \%$ & $(1.7)$ & $0.0 \%$ & $(1.6)$ & $-0.1 \%$ & $(1.7)$ \\
West & $-5.7 \%$ & $(1.3)$ & $-10.6 \%$ & $(1.2)$ & $-9.2 \%$ & $(1.4)$ & $-9.7 \%$ & $(1.3)$ \\
NYISO & $-3.9 \%$ & $(0.8)$ & $-10.3 \%$ & $(0.9)$ & $-10.4 \%$ & $(1.0)$ & $-7.9 \%$ & $(0.9)$ \\
\hline
\end{tabular}

Notes: This table shows average load reductions in relative terms caused by lockdown measures for weekdays only (03/23 to 05/04). Standard errors, taking account of the correlation of hourly errors within a day, are reported in parentheses.

Sheltering measures have also affected consumption timing. Figures $5 \mathrm{a}$ and $5 \mathrm{~b}$ show the daily load and the counterfactual load averaged from 03/23 to 04/13 (weeks 2 to 4) and from $04 / 14$ to $05 / 04$ (weeks 5 to 7 ) for weekdays and weekends, respectively. The morning peak turns out to be much flatter and reaches its maximum later. This pattern bears resemblance with what is usually observed during a widespread snow day (NYISO, 2020). Those changes are driven by increased demand from residential consumers and reduced commercial energy use. It may also suggest that lockdown measures affect sleeping patterns. For week-ends, results are suggestive of the large reduction in economic activities. 


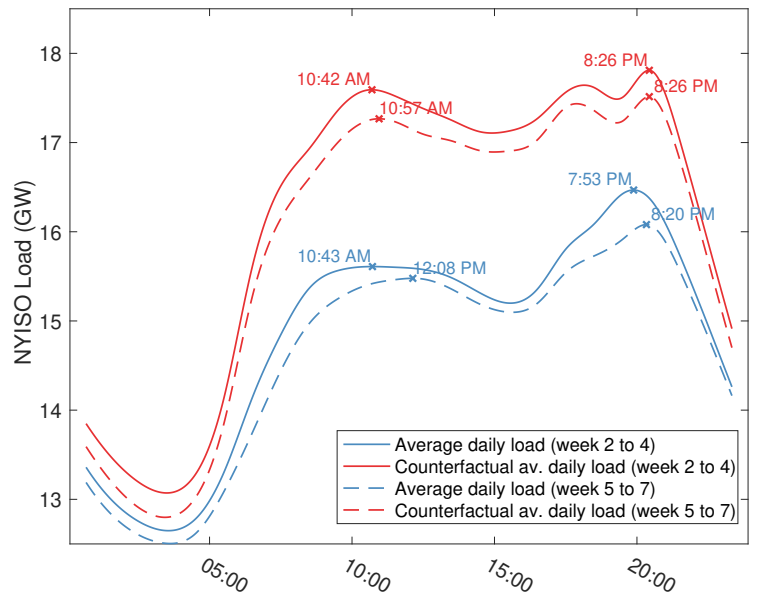

(a) Daily load patterns (weekdays)

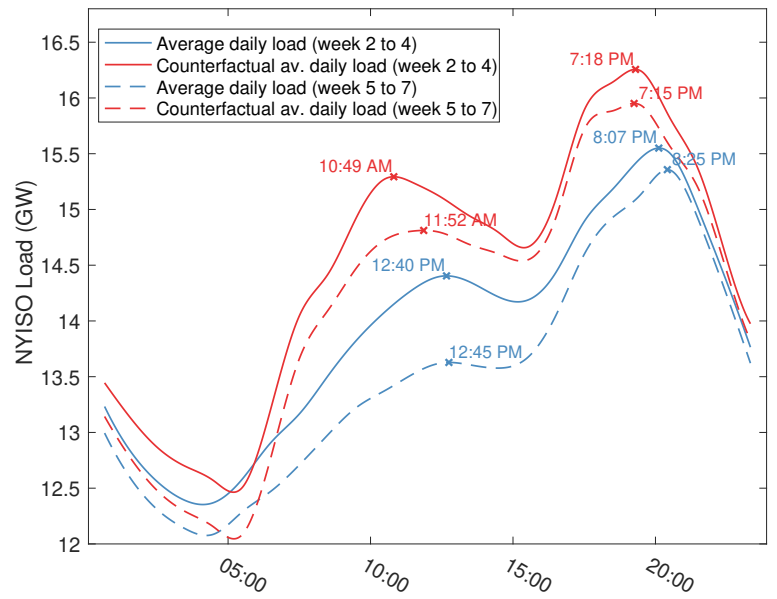

(b) Daily load patterns (weekends)

\section{Short-term market impacts}

In this section, we develop a methodology to estimate the impacts of demand reductions, forecast errors and fuel price drops on both the DA and RT markets. We consider this method as "semi-structural". It is structural in the sense that we claim to identify the main parameters which characterize the economic relations of interest. Nevertheless, a complete structural model would require additional assumptions. As our focus is on aggregate market outcomes, we use economic theory (Wolfram, 1999) to derive a specification for the industry-level supply curves. ${ }^{10}$

\subsection{Day-ahead market}

The DA prices are computed for every hour of the following day using zonal demand forecasts, energy bids submitted in each hourly auction, and transmission constraints. The prevailing DA price in any hour corresponds to the price bid of the marginal unit, i.e. the unit which is called into production with the highest-accepted bid price.

Nuclear power plants act as baseload and consistently bid at negative prices in order to maximize daily output whereas renewable power plants (i.e. solar and wind farms) do not submit bids per se and produce as much as possible given the realized weather

\footnotetext{
${ }^{10}$ Examples of more structural approach are to be found in Hortaçsu and Puller (2008), Reguant (2014) and Wolak (2003).
} 
conditions. Therefore, the marginal units in all hours are either hydro power plants, thermal generators, or imports from adjacent power systems. ${ }^{11}$

Specification. The bids submitted by generators are stacked into an aggregate supply function in ascending order, often referred to as the merit-order curve. It reflects the marginal willingness to accept of suppliers to generate different quantities of electricity.

Let $P_{t}^{D A}$ denote the DA price at time $t, M C(\cdot)$ the industry-level marginal cost function. Wolfram (1999) shows that taking the average of the first-order condition of firm-level profit-maximization problems across firms yields the industry-level supply relationship

$$
P_{t}^{D A}=\alpha M C\left(\bar{D}_{t}, Z_{t}, \varepsilon_{t} \mid \Theta\right)
$$

where $\bar{D}_{t}$ is the demand forecast, $\varepsilon_{t}$ is an error term, and $Z_{t}$ are marginal costs' shifters including: nuclear $N_{t}$ and renewable outputs $R_{t}$, the natural gas price $N G_{t}$ and $X_{t}$ includes a set of control variables for unexplained time variations: a linear time trend and time dummies for hours of day, days of the week and months. Finally $\alpha$ is a behavioral parameter depending on the degree of competition. ${ }^{12}$

Unlike Wolfram (1999), we focus on the aggregate supply function and are not interested in identifying $\alpha$. We specify the marginal cost function as a cubic polynomial function of the expected net demand, ${ }^{13}$, as given by

$$
M C\left(\bar{D}_{t}, Z_{t}, \varepsilon_{t}\right)=\sum_{i=1}^{3} \frac{\beta_{i}}{\alpha}\left(\bar{D}_{t}-N_{t}-R_{t}\right)^{i}+\frac{\gamma}{\alpha} N G_{t}+\frac{\delta}{\alpha} X_{t}+\varepsilon_{t}
$$

Combining (1) and (2) yields the regression equation

$$
P_{t}^{D A}=\sum_{i=1}^{3} \beta_{i}\left(\bar{D}_{t}-N_{t}-R_{t}\right)^{i}+\gamma N G_{t}+\delta X_{t}+\varepsilon_{t}
$$

\footnotetext{
${ }^{11}$ In some European countries, wind plants have also been marginal in a few hours during the lockdown period.

${ }^{12}$ More specifically, $\alpha=1$ under perfect competition whereas $\alpha=\frac{\eta-1}{\eta}$, with $\eta$ being the priceelasticity of demand if firms are Cournot oligopolists.

${ }^{13}$ The nuclear production is known ahead of production because of significant short-term ramping constraints. However the renewable output is subject to randomness and can differ a lot from its forecasts. Since we do not have wind forecast data, we use the actual values in the estimation.
} 
where the main parameters of interest are $\beta_{1}, \beta_{2}, \beta_{3}$ and $\gamma$.

Identification. The identification of $\beta$ 's and $\gamma$ requires that the error $\varepsilon_{t}$ be uncorrelated with the net load and local natural gas prices, conditionally on the other control variables. The first condition is likely to be satisfied empirically because demand forecasts, nuclear output and renewable production are virtually insensitive to DA prices. ${ }^{14}$ The second condition should hold in absence of a reverse causal effect from electricity prices to natural gas prices in New York. Nevertheless, electricity suppliers being large consumers of natural gas, it is possible that their aggregate demand affects the local price. $^{15}$

Estimation. The model specified in (3) is estimated using OLS on hourly observations from October 1, 2019 to May 31, 2020. ${ }^{16}$ Table 5 shows descriptive statistics for the main variables for both samples.

Table 5: Summary statistics

\begin{tabular}{lccccc}
\hline \hline & $P^{D A}$ & $P^{D A}-P^{R T}$ & $\bar{D}-N-R$ & $D-\bar{D}$ & $N G$ \\
\hline 01/01-03/15 & & & & & \\
Mean & 20.76 & -0.55 & 10.87 & -0.01 & 2.11 \\
Std & 7.31 & 9.49 & 2.16 & 0.35 & 0.70 \\
95th perc & 32.27 & 7.84 & 14.18 & 0.54 & 3.27 \\
5th perc & 12.50 & -10.17 & 7.17 & -0.48 & 1.28 \\
\hline 03/16-05/04 & & & & & \\
Mean & 14.22 & 0.18 & 9.96 & -0.36 & 1.45 \\
Std & 2.79 & 6.51 & 1.84 & 0.48 & 0.15 \\
95th perc & 19.16 & 6.70 & 13.00 & 0.39 & 1.77 \\
5th perc & 10.00 & -6.99 & 7.18 & -1.18 & 1.22 \\
\hline
\end{tabular}

Notes: This table shows means, standard deviations, 95 th percentile and 5 th percentile for the DA price (in $\$ / M W h$ ), forward premium (in $\$ / M W h$ ), net load (in $G W h$ ), forecast errors (in GWh), natural gas prices (in $\$ / M M B t u$ ), for both samples.

\footnotetext{
${ }^{14}$ If endogeneity of demand is suspected, there are plenty of demand shifters available related to weather conditions.

${ }^{15} \mathrm{~A}$ solution to this problem would be to use Hausman-type instruments such as prices at Henry hub.

${ }^{16}$ We also consider shorter time periods and do not find substantial differences.
} 
Table 6 reports the regression estimates, associated standard errors, and goodnessof-fit statistics for the three main zones and the entire NYISO. The coefficients associated with the net load and natural gas price are found to be statistically significant in all zones.

Table 6: Regression results DAM $(\$)$

\begin{tabular}{lcccc}
\hline \hline & Long Isl. & Mohawk V. & NYC & NYISO \\
\hline Netload & 17.63 & 25.82 & 17.80 & 16.54 \\
& $(6.88)$ & $(16.91)$ & $(7.01)$ & $(6.56)$ \\
Netload $^{2}$ & -1.59 & -2.44 & -1.60 & -1.47 \\
& $(0.70)$ & $(1.73)$ & $(0.71)$ & $(0.67)$ \\
Netload $^{3}$ & 0.05 & 0.08 & 0.05 & 0.05 \\
& $(0.02)$ & $(0.06)$ & $(0.02)$ & $(0.02)$ \\
Nat.gas & 3.17 & 4.56 & 3.19 & 2.43 \\
& $(0.90)$ & $(1.61)$ & $(0.92)$ & $(0.73)$ \\
Obs & 5565 & 5565 & 5565 & 5565 \\
$R^{2}$ & 0.71 & 0.64 & 0.71 & 0.75 \\
\hline
\end{tabular}

Notes: This table reports the estimated parameters, standard errors (in parentheses), and goodness-of-fit statistics for the estimation of model (3). The dependent variable is the DA price. Standard errors are robust to arbitrary autocorrelation (including 24 lags) and heteroskedasticity.

\subsection{Real-time market}

The RT prices are computed for every 5 minutes during each day of operation using realized demands in all zones, RT energy bids and transmission constraints. This price corresponds to the price bid of the marginal unit called to ramp up or down its production for balancing purposes. This analysis focuses on the hourly RT price which is calculated as a load-weighted average price of the 5-min intervals.

Specification. In the economics literature, the equilibrium characterization of the RT price, denoted $P_{t}^{R T}$, depends on $P_{t}^{D A}$ (Benatia and Billette de Villemeur, 2019; Ito and Reguant, 2016). More specifically, economic theory shows that the forward premium $P_{t}^{D A}-P_{t}^{R T}$ is positively related with the difference between the expected demand and its realization $D_{t}^{D A}-D_{t}^{R T}$.

The cost parameters are different in the real-time market because of the existence 
of ramping costs. Behavioral parameters may also differ as the degree of competition is not necessarily the same across sequential markets. We specify the aggregate offer curve for near real-time supply as a cubic polynomial of net demand and. In addition, we consider that competition in the RT market may depend on the realized DA price. The counterpart of (3) for real-time prices is hence given by

$$
P_{t}^{R T}=(\theta-1) P_{t}^{D A}+\sum_{i=1}^{3} \beta_{i}^{R T}\left(D_{t}-N_{t}-R_{t}\right)^{i}+\gamma^{R T} N G_{t}+\delta^{R T} X_{t}+\varepsilon_{t}^{R T} .
$$

Subtracting (3) to (4) and rearranging yields the regression model

$$
P_{t}^{R T}=\theta P_{t}^{D A}+\sum_{i=1}^{3} \beta_{i}^{R T}\left(D_{t}^{i}-\bar{D}_{t}^{i}\right)-\sum_{i=1}^{3} \Delta \beta_{i}\left(\bar{D}_{t}-N_{t}-R_{t}\right)^{i}+\Delta \gamma N G_{t}+\Delta \delta X_{t}+\Delta \varepsilon_{t}
$$

where $\Delta$ denotes differences, e.g. $\Delta \gamma=\gamma^{R T}-\gamma$. The main parameters of interest are the $\beta^{R T}$ 's which capture the effects of forecast errors on the RT price. $\theta$ and $\Delta \beta^{\prime}$ 's will be used to characterize how the RT supply function changes with the DA market outcome.

Identification. The identification of $\beta^{R T}$ 's requires that the error $\Delta \varepsilon_{t}$ be uncorrelated with the forecast errors. Load forecasting is centralized by the system operator and chronic over- or under- forecasters are penalized to prevent strategic behaviors. We assume these penalties to be well-designed so as to curb potential strategic behaviors. An orthogonality condition should also hold with respect to $N G_{t}$ because demand of natural gas for grid balancing purposes is small with respect to the market size. However, there could be weather conditions, such as winter storms, correlated with both local gas prices and the forward premium. ${ }^{17}$

Estimation. Equation (5) is estimated with OLS using hourly observations from October 1, 2019 to May 31, 2020. Table 7 reports the regression results. The coefficients

\footnotetext{
${ }^{17}$ Endogeneity issues can be addressed using IV regressions as discussed for the DA market. Note that, however, the identification of $\theta$ is not guaranteed given that $P^{D A}$ is correlated with $\Delta \varepsilon_{t}$ by construction. Estimates obtained when fixing $\theta=1$ being nearly unchanged, we neglect this potential issue.
} 
associated with the DA price, forecast errors and net loads are found to be statistically significant predictors for all zones. The coefficient for natural gas is never significant at $5 \%$ in any zone.

Table 7: Regression results (5)

\begin{tabular}{|c|c|c|c|c|}
\hline \multirow{3}{*}{$P^{D A}$} & Long Isl. & Mohawk V. & NYC & NYISO \\
\hline & 0.83 & 0.78 & 0.83 & 0.84 \\
\hline & $(0.08)$ & $(0.12)$ & $(0.08)$ & $(0.13)$ \\
\hline \multirow[t]{2}{*}{$D-\bar{D}$} & 120.53 & 104.13 & 142.36 & 66.58 \\
\hline & $(37.35)$ & $(42.09)$ & $(43.05)$ & $(22.52)$ \\
\hline$D^{2}-\bar{D}^{2}$ & $\begin{array}{l}-7.44 \\
(2.26)\end{array}$ & $\begin{array}{l}-6.38 \\
(2.52)\end{array}$ & $\begin{array}{l}-8.81 \\
(2.62)\end{array}$ & $\begin{array}{l}-4.13 \\
(1.35)\end{array}$ \\
\hline \multirow[t]{2}{*}{$D^{3}-\bar{D}^{3}$} & 0.16 & 0.14 & 0.18 & 0.09 \\
\hline & $(0.04)$ & $(0.05)$ & $(0.05)$ & $(0.03)$ \\
\hline - Netload & $\begin{array}{c}-22.65 \\
(6.33)\end{array}$ & $\begin{array}{l}-32.52 \\
(12.23)\end{array}$ & $\begin{array}{c}-23.87 \\
(6.52)\end{array}$ & $\begin{array}{c}-19.14 \\
(5.53)\end{array}$ \\
\hline- Netload $^{2}$ & $\begin{array}{c}2.22 \\
(0.63)\end{array}$ & $\begin{array}{c}3.21 \\
(1.29)\end{array}$ & $\begin{array}{c}2.34 \\
(0.65)\end{array}$ & $\begin{array}{l}1.87 \\
(0.55)\end{array}$ \\
\hline- Netload $^{3}$ & $\begin{array}{l}-0.07 \\
(0.02)\end{array}$ & $\begin{array}{l}-0.11 \\
(0.04)\end{array}$ & $\begin{array}{l}-0.08 \\
(0.02)\end{array}$ & $\begin{array}{l}-0.06 \\
(0.02)\end{array}$ \\
\hline Nat.gas & $\begin{array}{c}1.31 \\
(1.03)\end{array}$ & $\begin{array}{c}4.14 \\
(2.19)\end{array}$ & $\begin{array}{c}1.26 \\
(1.06)\end{array}$ & $\begin{array}{l}1.10 \\
(0.76)\end{array}$ \\
\hline Obs & 5565 & 5565 & 5565 & 5565 \\
\hline$R^{2}$ & 0.51 & 0.47 & 0.52 & 0.52 \\
\hline
\end{tabular}

Notes: This table reports the estimated parameters, standard errors (in parentheses), and goodness-of-fit statistics for the estimation of model (5). The dependent variable is the forward premium. Standard errors are robust to arbitrary autocorrelation (including 24 lags) and heteroskedasticity.

Figure 6 shows the estimated aggregate supply curves in the DA and RT markets for NYISO (all zones pooled). The RT supply curve is shown for forecast errors from -2500 to $2500 \mathrm{MWh}$ around an expected net load of $10 \mathrm{GWh}$, which corresponds to the average net load during the lockdown period.

The polynomial specification yields a good fit of DA prices. We find that negative DA prices may occur only at extremely low net demand levels (below $6 \mathrm{GWh}$ ). Negative RT prices can be the consequence of over-forecasting when demand is relatively low. The shape of the RT supply curve captures the ramping costs of thermal producers: if 
the realized demand turns out to be much smaller than expected, some power plants may have to shut down at least temporarily - which comes at significant costs.

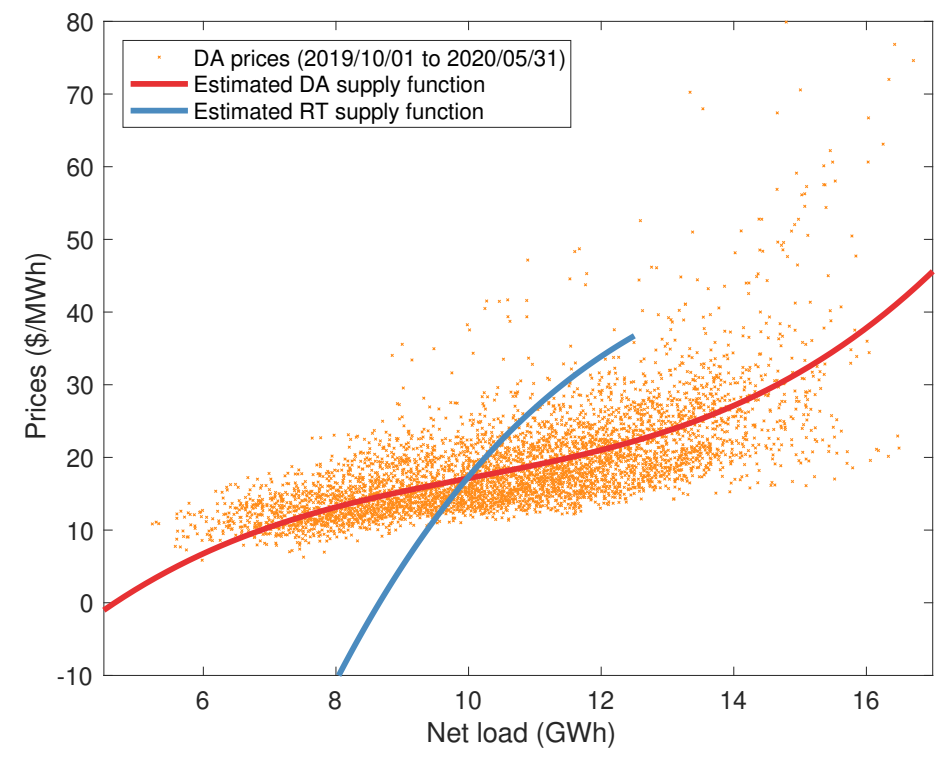

Figure 6: Estimated DA and RT aggregate supply functions

\subsection{Short-term consequences}

In this section, the estimated parameters are used to investigate counterfactual scenarios. In the short-term, there are four main effects: 1 . the electricity demand reductions caused by containment measures, 2 . the drop in natural gas prices caused by the global energy demand reductions, 3. the coincidental retirement of a 1,200 MW nuclear power generating unit during March-April 2020, and 4. the surge of forecast errors due to the new load pattern under lockdown. For clarity, we use the standard notations of the potential outcomes framework, where variables indexed by (1) have received the treatment and those indexed by (0) have not. The considered treatment will vary across scenarios.

Counterfactual scenario 1: no lockdown. First, we study the impact of demand reductions using our estimates of the counterfactual demand obtained in Section 2. The counterfactual DA price assuming that demand reductions due to containment measures had not occurred is calculated as 


$$
\widehat{P}_{t}^{D A}(0)=P_{t}^{D A}(1)+\sum_{i=1}^{3} \hat{\beta}_{i}\left[\left(\widehat{D}_{t}^{D A}(0)-N_{t}-R_{t}\right)^{i}-\left(D_{t}^{D A}(1)-N_{t}-R_{t}\right)^{i}\right]
$$

where $\widehat{P}_{t}^{D A}(0)$ is the counterfactual DA price, $\widehat{D}_{t}^{D A}(0)$ is the estimated counterfactual demand using NNet and $P_{t}^{D A}(1)$ and $D_{t}^{D A}(1)$ are the observed realizations during the lockdown period. Using (5), the counterfactual RT price is given by

$$
\begin{aligned}
\widehat{P}_{t}^{R T}(0)= & P_{t}^{R T}(1)-\hat{\theta}\left(\widehat{P}_{t}^{D A}(0)-P_{t}^{D A}(1)\right) \\
& +\sum_{i=1}^{3} \widehat{\Delta \beta}_{i}\left[\left(\widehat{D}_{t}^{D A}(0)-N_{t}-R_{t}\right)^{i}-\left(D_{t}^{D A}(1)-N_{t}-R_{t}\right)^{i}\right]
\end{aligned}
$$

Counterfactual scenario 2: no natural gas price drop. Second, we study the impact of the natural gas price reductions by assuming a counterfactual price $N G_{t}(0)=$ $1.86(\$ / \mathrm{MMBtu})$, the average during February 2020. All other variables are kept unchanged. Figure 7 shows the time-series of natural gas prices in New York as well as the counterfactual price assumed in this scenario. The counterfactual prices are computed using the same approach as for scenario 1 . We neglect the direct effect of natural gas prices on RT prices, as captured by the parameter $\gamma_{R T}$ in (5) because it is not significant in all zones. The average t-statistic is 1.04 . 


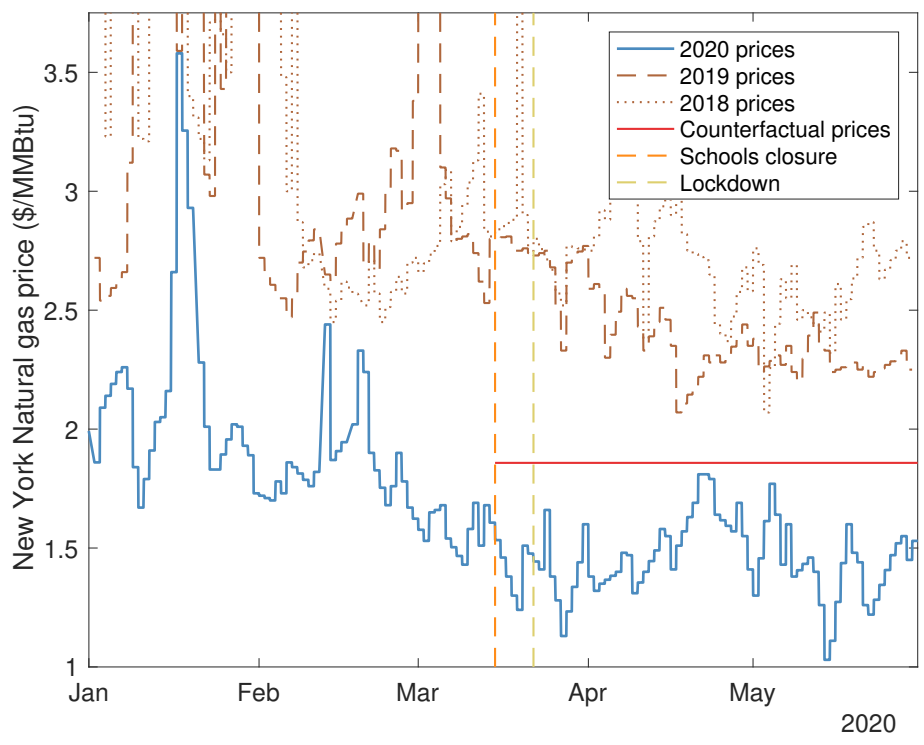

Figure 7: Natural gas prices

Counterfactual scenario 3: no nuclear plant phase-out. Third, the effect of the nuclear plant phase-out is evaluated by assuming that the plant was available. Figure 8 shows that a drop of nuclear output of around 1,200 MW occurred early March as Indian Point 2 was taken offline. The unit was ramped up again during April before its final retirement at the end of the month. During this period, the nuclear output decreased almost linearly until early May - except for a temporary ramp-up, and then remained constant throughout the rest of the period. As a counterfactual, we assume that the nuclear production in absence of the Indian Point 2 phase-out, denoted $\widehat{N}_{t}(0)$, would have followed the production schedule depicted in Figure 8. Associated counterfactual prices are computed by changing only this variable and keeping the others fixed. 


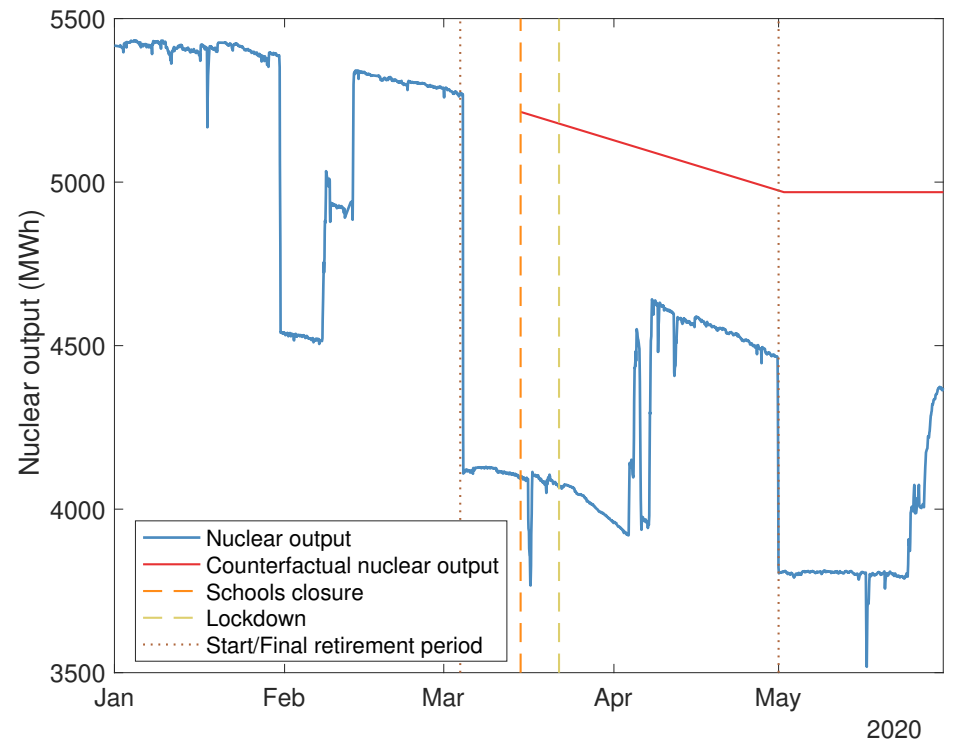

Figure 8: Nuclear power

Counterfactual scenario 4: "business-as-usual" forecast errors. Forecast errors do affect RT prices but not DA prices. We hence assume $\widehat{P}_{t}^{D A}(0)=P_{t}^{D A}(1)$ in this scenario. There are many possible counterfactual scenario for forecast errors. We propose to define "business-as-usual" errors $F E_{t}(0)$ by transforming the observed errors $F E_{t}(1)$ so that they have the same distribution than before the schools closure on March 16, 2020. The counterfactual errors are defined as

$$
\widehat{F E}_{t}(0)=\frac{\sigma_{F E}(0)}{\sigma_{F E}(1)} F E_{t}(1)-(\overline{F E}(1)-\overline{F E}(0))
$$

where $\overline{F E}(0)$ and $\sigma_{F E}(0)$ are the mean and standard error of forecast errors from January 1 to March 15, 2020. The distribution of forecast errors may not have been fixed during the whole lockdown period as algorithms were adjusted. We compute the corresponding statistics $\overline{F E}(1)$ and $\sigma_{F E}(1)$ separetely for each week from March 16 to May 31, 2020. Figure 9 shows the time-series (18-hours moving average) of forecast errors and its counterfactual values. The associated RT price in this scenario is

$$
\widehat{P}_{t}^{R T}(0)=P_{t}^{R T}(1)-\sum_{i=1}^{3} \widehat{\beta}_{i}^{R T}\left[\widehat{F E}_{t}(0)^{i}-F E_{t}(1)^{i}\right]
$$




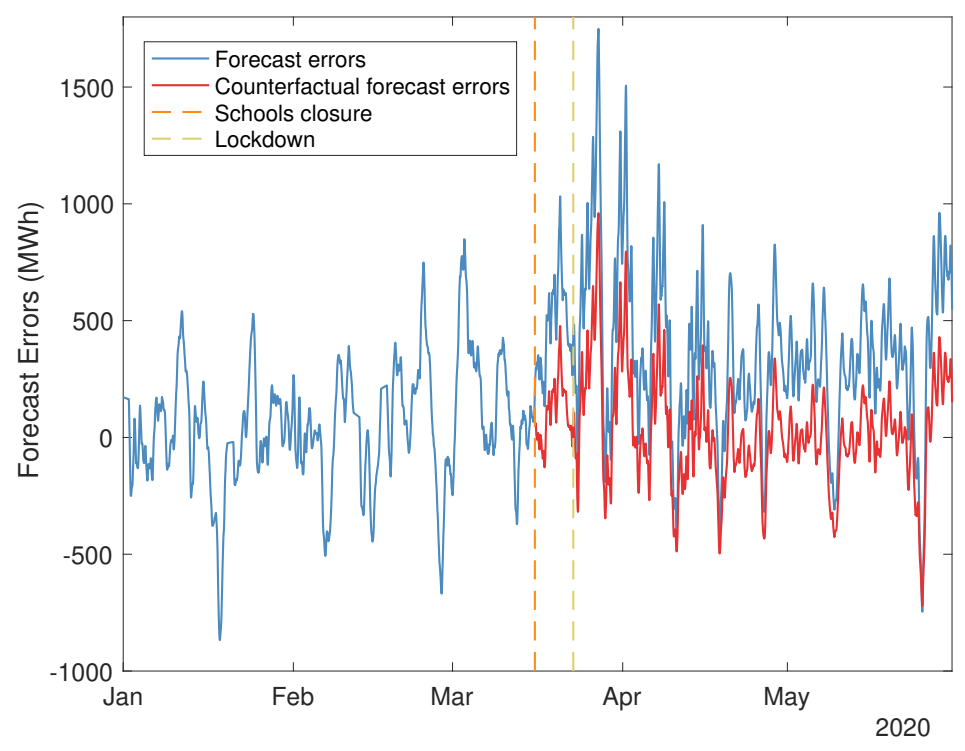

Figure 9: Forecast errors

Day-ahead prices. We find that DA prices have significantly decreased because of the demand reductions and fuel price drops. Part of this reduction was compensated by Indian Point 2 going offline. Table 8 reports the $95 \%$ confidence interval on changes in NYISO prices had demand reductions not occurred (column 1), and similarly for fuel price reductions (column 2), and nuclear phase-out (column 3). There are statistically significant price differences in each of three scenarios in all 7 weeks following the schools closure. In the last column, all three effects are combined. We find that in all but three weeks, the nuclear phase-out has compensated the price reductions caused by the lockdown and natural gas price drops on average. 
Table 8: DAM Average price impacts (\$)

\begin{tabular}{lcccc}
\hline \hline & Lockdown & Nat. gas & Nuclear & All \\
\hline $03 / 16-03 / 22$ & {$[-1.1,-0.5]$} & {$[-1.8,-0.5]$} & {$[+2.0,+3.0]$} & {$[-0.1,+1.6]$} \\
$03 / 23-03 / 29$ & {$[-1.8,-0.9]$} & {$[-2.0,-0.5]$} & {$[+2.0,+3.0]$} & {$[-0.9,+1.0]$} \\
$03 / 30-04 / 05$ & {$[-1.5,-0.9]$} & {$[-1.7,-0.5]$} & {$[+1.8,+2.8]$} & {$[-0.7,+1.0]$} \\
$04 / 06-04 / 12$ & {$[-2.0,-1.3]$} & {$[-1.7,-0.4]$} & {$[+1.1,+1.8]$} & {$[-2.1,-0.6]$} \\
$04 / 13-04 / 19$ & {$[-2.5,-1.6]$} & {$[-1.3,-0.3]$} & {$[+0.8,+1.4]$} & {$[-2.4,-1.2]$} \\
$04 / 20-04 / 26$ & {$[-1.8,-1.2]$} & {$[-0.6,-0.2]$} & {$[+0.8,+1.3]$} & {$[-1.1,-0.5]$} \\
$04 / 27-05 / 04$ & {$[-1.7,-1.1]$} & {$[-1.3,-0.3]$} & {$[+1.4,+2.3]$} & {$[-1.1,+0.3]$} \\
$05 / 05-05 / 10$ & {$[-1.9,-1.3]$} & {$[-1.3,-0.3]$} & {$[+2.0,+3.0]$} & {$[-0.7,+0.9]$} \\
$05 / 11-05 / 18$ & {$[-2.6,-1.5]$} & {$[-2.2,-0.6]$} & {$[+2.0,+2.9]$} & {$[-1.7,+0.3]$} \\
$05 / 19-05 / 24$ & {$[-2.3,-1.4]$} & {$[-1.9,-0.5]$} & {$[+2.0,+3.2]$} & {$[-1.2,+0.8]$} \\
$05 / 25-05 / 31$ & {$[-1.4,+0.6]$} & {$[-1.4,-0.4]$} & {$[+1.4,+3.3]$} & {$[-0.0,+2.2]$} \\
\hline
\end{tabular}

Notes: This table shows the $95 \%$ confidence interval for the average impacts (in $\$$ ) of each counterfactual on DA prices separately for all eleven weeks after schools closure.

From March 16 to May 31, DA prices decreased by $15 \%$ on average with respect to counterfactual levels with neither lockdown nor fuel price drops. $40 \%$ of this decrease is attributed to the lockdown whereas $60 \%$ is attributed to lower gas prices. Figure 10 shows observed prices and counterfactual prices from scenario 1 (no lockdown), and combined with scenario 2 (no lockdown and no gas price drops).

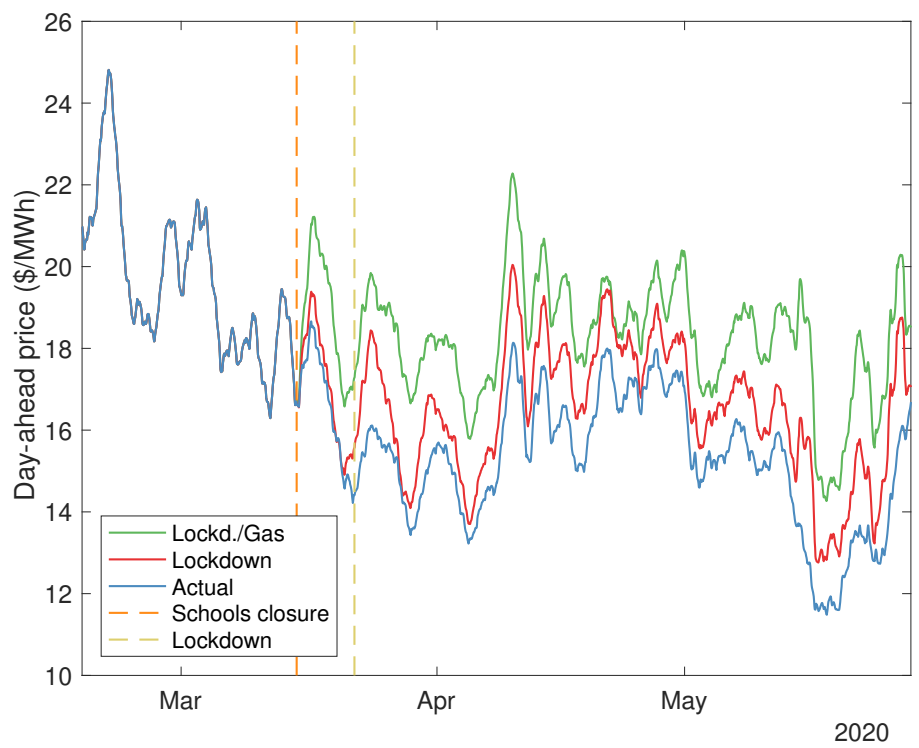

Figure 10: Actual and counterfactual day-ahead prices 
Real-time prices. RT prices have decreased as a result of larger forecast errors $\left(F E_{t}(0)<F E_{t}(1)\right)$ and depressed DA prices $\left(P_{t}^{D A}(0)>P_{t}^{D A}(1)\right)$. These effects can be seen from (9) and (8). Table 9 reports the $95 \%$ confidence interval for the effects on NYISO prices of having "business-as-usual" forecast errors (column 1), and "lifting" the lockdown (column 2), fuel price reduction (column 3), and nuclear phase-out (column 4). There are statistically significant price differences in most of these scenarios in all weeks following the schools closure. In the last column, all four effects are combined. There were several weeks during which the combined effects are not significantly different from zero.

Table 9: RTM Average price impacts $(\$)$

\begin{tabular}{lccccc}
\hline \hline & Forec. errors & Lockdown & Nat. gas & Nuclear & All \\
\hline $03 / 16-03 / 22$ & {$[-2.6,-1.3]$} & {$[-1.6,-0.5]$} & {$[-1.2,-0.6]$} & {$[+2.4,+3.9]$} & {$[-1.5,+0.4]$} \\
$03 / 23-03 / 29$ & {$[-3.0,-1.4]$} & {$[-2.8,-1.1]$} & {$[-1.4,-0.7]$} & {$[+2.4,+3.9]$} & {$[-2.6,-0.6]$} \\
$03 / 30-04 / 05$ & {$[-2.7,-1.3]$} & {$[-2.3,-0.8]$} & {$[-1.2,-0.6]$} & {$[+2.2,+3.5]$} & {$[-2.3,-0.5]$} \\
$04 / 06-04 / 12$ & {$[-1.6,-0.8]$} & {$[-3.0,-1.0]$} & {$[-1.2,-0.6]$} & {$[+1.4,+2.4]$} & {$[-3.4,-1.4]$} \\
$04 / 13-04 / 19$ & {$[-1.3,-0.6]$} & {$[-3.7,-1.3]$} & {$[-0.9,-0.5]$} & {$[+1.0,+1.9]$} & {$[-3.8,-1.6]$} \\
$04 / 20-04 / 26$ & {$[-1.5,-0.7]$} & {$[-2.7,-0.8]$} & {$[-0.4,-0.2]$} & {$[+0.8,+1.7]$} & {$[-2.7,-0.8]$} \\
$04 / 27-05 / 04$ & {$[-2.3,-0.9]$} & {$[-2.4,-0.7]$} & {$[-0.9,-0.5]$} & {$[+1.8,+3.0]$} & {$[-2.6,-0.6]$} \\
$05 / 05-05 / 10$ & {$[-1.3,-0.6]$} & {$[-2.8,-0.9]$} & {$[-0.9,-0.5]$} & {$[+2.4,+3.8]$} & {$[-1.2,+0.4]$} \\
$05 / 11-05 / 18$ & {$[-2.0,-0.9]$} & {$[-3.8,-1.4]$} & {$[-1.5,-0.8]$} & {$[+2.1,+3.7]$} & {$[-3.0,-0.6]$} \\
$05 / 19-05 / 24$ & {$[-1.9,-0.8]$} & {$[-3.4,-1.3]$} & {$[-1.3,-0.7]$} & {$[+2.5,+4.2]$} & {$[-2.2,-0.0]$} \\
$05 / 25-05 / 31$ & {$[-3.0,-1.7]$} & {$[-2.2,+0.8]$} & {$[-1.0,-0.5]$} & {$[+2.4,+4.6]$} & {$[-1.7,+1.5]$} \\
\hline
\end{tabular}

Notes: This table shows the $95 \%$ confidence interval for the average impacts (in $\$$ ) of each counterfactual on RT prices separately for all eleven weeks after schools closure.

From March 16,2020 to May 4, RT prices decreased by 23\% on average with respect to counterfactual levels with neither abnormal errors, nor lockdown and gas price drops. Figure 11 shows observed prices and counterfactual prices from scenario 4 (no abnormal errors), and combined with scenarios 1 and 2 (no abnormal errors, no lockdown and no gas price drops). 


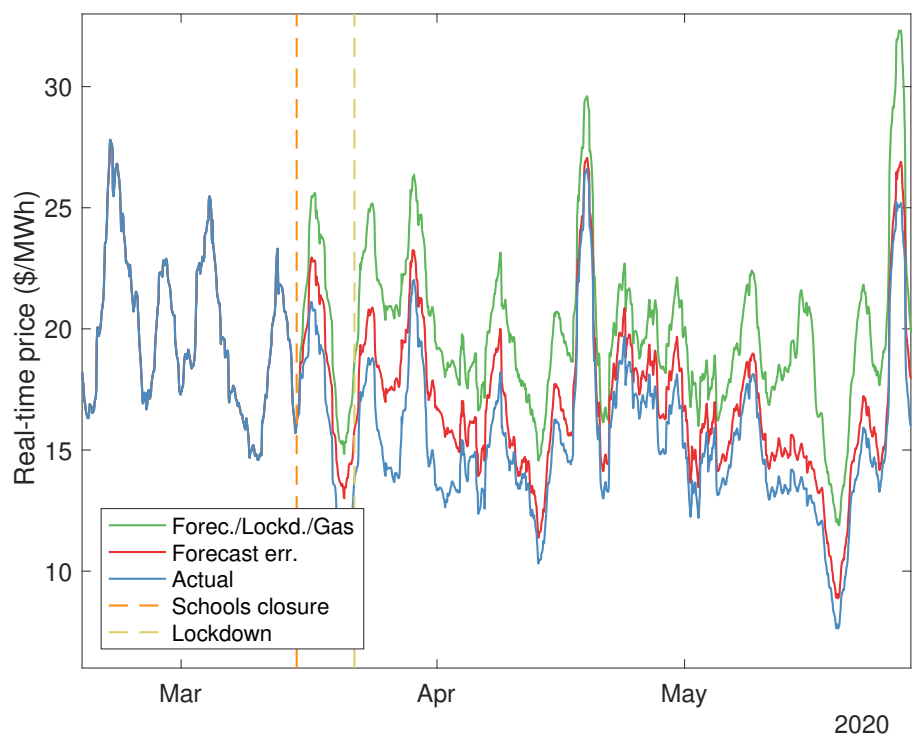

Figure 11: Actual and counterfactual real-time prices

Day-ahead market values. The value of the day-ahead market in every hour $t$ is defined as

$$
\operatorname{Value}_{t}^{D A}=\sum_{z=1}^{11} P_{z t}^{D A} \times D_{z t}^{D A},
$$

that is the sum of the market value of zonal exchanges, where $z=1, \ldots, 11$ denotes a load zone.

Table 10 reports the realized market values for all 11 weeks and under the counterfactual scenarios. The total market value using observed prices and zonal electricity demands is $\$ 398$ million. Had the lockdown not been enacted, both demand and price would have been larger and the market value would have been about $\$ 460$ million. In absence of a fuel price drop, in addition to the previous effect, would have pushed prices further up, and increased market value up to $\$ 488$ million. The cost of the crisis for electricity suppliers for the DA market alone amounts to a reduction of around $18.5 \%$ of gross revenues. ${ }^{18}$

\footnotetext{
${ }^{18}$ This valuation neglects the existence of forward contracts and redistribution between producers and large buyers.
} 
Table 10: Weekly day-ahead market values (\$ million)

\begin{tabular}{|c|c|c|c|c|c|c|c|c|c|c|c|c|}
\hline & \multicolumn{11}{|c|}{ Week from $03 / 16$ to $05 / 31$} & \multirow[b]{2}{*}{ Tot. } \\
\hline & 1 & 2 & 3 & 4 & 5 & 6 & 7 & 8 & 9 & 10 & 11 & \\
\hline Actual & 43 & 40 & 37 & 33 & 33 & 37 & 37 & 35 & 32 & 30 & 43 & 398 \\
\hline Lockdown & 46 & 45 & 42 & 39 & 41 & 43 & 42 & 40 & 40 & 37 & 45 & 460 \\
\hline Gas & 46 & 43 & 40 & 35 & 35 & 38 & 39 & 37 & 35 & 33 & 45 & 425 \\
\hline Nuclear & 36 & 33 & 31 & 29 & 30 & 35 & 33 & 29 & 26 & 24 & 36 & 342 \\
\hline Lockd./Gas/Nuclear & 42 & 41 & 38 & 38 & 40 & 41 & 40 & 36 & 36 & 33 & 40 & 427 \\
\hline Lockd./Gas & 49 & 48 & 45 & 42 & 43 & 44 & 45 & 42 & 43 & 40 & 47 & 488 \\
\hline
\end{tabular}

Notes: This table shows the total DA market value in $\$$ million in each counterfactual separately for all eleven weeks after schools closure.

Real-time market values. The value of the real-time market in every hour $t$ is defined as

$$
\operatorname{Value}_{t}^{R T}=\sum_{z=1}^{11} P_{z t}^{R T} \times\left|D_{z t}^{D A}-D_{z t}^{R T}\right|,
$$

that is the sum of the market value of zonal forecast errors, which corresponds to the amount of exchanges on the balancing market.

Table 11 reports the market values for all 11 weeks in various scenarios. The total market value using observed prices and zonal electricity demands is $\$ 16.3$ million, that is roughly $4 \%$ of the DA market value. Had forecast errors remained as usual, the demand for real-time balancing would have been smaller and the market value would have been about $\$ 10.8$ million. If there had not been demand reductions and fuel price drops, in addition to the previous effect, the market value would have been down to $\$ 12.6$ million. The RT market is hence found to have appreciated by nearly $28 \%$. Therefore, some electricity suppliers providing balancing services in the RT market may have gained larger revenues during this crisis. 
Table 11: Weekly real-time market values (\$ million)

\begin{tabular}{lcccccccccccc}
\hline \hline & \multicolumn{11}{c}{ Week from $03 / 16$ to $05 / 31$} \\
& 1 & 2 & 3 & 4 & 5 & 6 & 7 & 8 & 9 & 10 & 11 & Tot. \\
\hline Actual & 1.7 & 2.3 & 1.7 & 1.5 & 1.3 & 1.2 & 1.3 & 1.3 & 1.1 & 1.0 & 1.9 & 16.3 \\
Forec. err. & 1.1 & 1.6 & 1.2 & 1.1 & 1.0 & 0.8 & 0.8 & 0.9 & 0.6 & 0.6 & 1.2 & 10.8 \\
Lockdown & 1.8 & 2.6 & 1.9 & 1.8 & 1.6 & 1.4 & 1.4 & 1.4 & 1.3 & 1.2 & 2.0 & 18.4 \\
Gas & 1.8 & 2.5 & 1.8 & 1.6 & 1.4 & 1.2 & 1.3 & 1.3 & 1.2 & 1.1 & 2.0 & 17.2 \\
Nuclear & 1.3 & 1.9 & 1.3 & 1.3 & 1.2 & 1.1 & 1.1 & 1.0 & 0.8 & 0.8 & 1.4 & 13.3 \\
For./Loc./Gas/Nuc. & 1.0 & 1.6 & 1.1 & 1.1 & 1.1 & 0.8 & 0.8 & 0.8 & 0.6 & 0.6 & 1.1 & 10.7 \\
Forec./Lockd./Gas & 1.2 & 1.9 & 1.4 & 1.3 & 1.2 & 0.9 & 0.9 & 1.0 & 0.8 & 0.8 & 1.3 & 12.6 \\
\hline
\end{tabular}

Notes: This table shows the total RT market value in $\$$ million in each counterfactual separately for all eleven weeks after schools closure.

Total market values. Finally, adding up the values from the two markets yields an estimate of the total value of the NY electricity market during the crisis. Table 12 shows that the total market value has depreciated by $\$ 87$ million, i.e. $18 \%$, during this period, leaving many market participants with substantially lower revenues than usual. Obviously, there were winners and losers, and some energy producers offering balancing services in the RT market may have been able to mitigate some of their losses. It is difficult to draw a precise conclusion for each firm without having access to their forward contracts and respective market positions. However, it is likely that the profitability of baseload assets has reduced given the lower competitive rents.

Table 12: Weekly total market values (\$ million)

\begin{tabular}{lcccccccccccc}
\hline \hline & \multicolumn{11}{c}{ Week from $03 / 16$ to $05 / 31$} \\
& 1 & 2 & 3 & 4 & 5 & 6 & 7 & 8 & 9 & 10 & 11 & Tot. \\
\hline Actual & 45 & 42 & 39 & 34 & 34 & 38 & 38 & 36 & 33 & 31 & 45 & 414 \\
Forec./Lockd./Gas & 50 & 50 & 46 & 43 & 44 & 45 & 46 & 43 & 44 & 41 & 48 & 501 \\
\hline
\end{tabular}

Notes: This table shows the total market value in $\$$ million in each counterfactual separately for all eleven weeks after schools closure.

\section{Discussion}

As epidemiologists predict future waves of COVID-19 cases and the need for other rounds of containment measures, stakeholders must find solutions to mitigate their 
effects on the economy. In this section, we identify the main issues that need to be addressed.

Short-term concern 1: Seasonality matters. The short-term consequences on electricity markets have been moderate so far in New York. We estimate that the demand and price reductions led to a substantial reduction in gross revenues for suppliers. This estimate extrapolates to nearly $\$ 2.6$ billion for the entire US, assuming the New York State is somehow representative in terms of costs of supplying electricity and demand reductions. However, March-April is a low demand period where prices are usually stable and low. The economic consequences will be undoubtedly larger if similar events happen closer to the summer or winter peaks, or in markets with larger penetration of renewable energy, when prices are more sensitive to demand or supply disruptions and forecast errors.

Short-term concern 2: Limits of forecasting models. The short-term forecasting model used by NYISO is found to have adjusted within 4 weeks after the schools closure. The demand forecast was persistently biased upward during that period. The surge in forecast errors has led to an increased, and widely inefficient, reliance on the real-time market. This result is symptomatic of the forecasting algorithms' inability to quickly adapt after structural changes. Improvements will be needed in a timely manner to prevent inefficient resource allocations.

Long-term concern 1: Risk mitigation. The current crisis is depressing prices faster than anticipated. The low price environment may slow new capacity additions as investors update their expectations about future market conditions. In many markets, the profitability issue of new investment may become more pressing. The current crisis must act as a warning signal about the needs for reforms. Meeting ambitious renewable targets will become more challenging in absence of market design adjustments to ensure systems adequacy (Newbery et al., 2018).

Long-term concern 2: Increased borrowing costs. The most pressing issue for utilities in the U.S. is perhaps the suspension of $\$ 6.4$ billion in pending rate hikes. It 
was announced in many states, including New York, as a measure to protect the most vulnerable populations during the crisis. Although it is a good news for residential consumers in the short-term, rate recovery of fixed-costs for utilities is essential to guarantee reasonable borrowing costs for large capital projects. The combination of delayed rate hikes and the financial struggle of energy consumers caused by containment measures may increase the cost of capital and ultimately affect energy bills in the long term.

\section{Conclusion}

We study the pandemic's consequences on electricity markets. Our empirical framework allows to quantify the effects of the crisis on demand, forecast errors, day-ahead and real-time markets. We show that the total effect on the New York electricity market is large, although not as large as in other economic sectors and other countries.

The unparalleled changes in daily load patterns have depressed wholesale prices, reduced gross revenues for suppliers, and undermined system efficiency. As demand and prices reach new lows, there will be needs for regulatory adjustments. New mobility data resources, for instance Google's Community Mobility Reports, offer opportunities to address inefficiencies resulting from increased forecast errors.

There are additional effects not studied in the paper. First, the economic costs of increased forecast errors comes not only from balancing costs (real-time markets) but also from additional payments for ancillary services. Second, containment measures have delayed the commissioning of current projects (renewable capacity additions, refurbishment of transmission lines, equipment maintenance, etc.) as all non-essential works were on pause. Those delays could have detrimental consequences for small firms with tighter credit constraints.

Finally, system operators have to come up with pandemic response plans to ensure the security of supply and safety of their employees. NYISO has perhaps implemented the starkest measures: 37 operators, managers and support staff volunteered for total sequestration from the outside world until further notice. "Just like planes can't fly without pilots and co-pilots, the electric system can't run without electricity operators", said NYISO's Vice-President of Operations. 


\section{References}

AESO. 2020. "Impacts of the COVID-19 Pandemic and Low Oil Prices on Alberta's Power System." AESO. https://www.aeso.ca/assets/Uploads/ Pandemic-Low-Oil-Analysis-Summary-April-20-Final.pdf, accessed May 2020.

Ambec, Stefan, and Claude Crampes. 2012. "Electricity Provision with Intermittent Sources of Energy." Resource and Energy Economics, 34(3): 319-336.

Benatia, David. 2018. "Functional Econometrics of Multi-Unit Auctions: an Application to the New York Electricity Market." Working Paper.

Benatia, David. 2020. "Electricity Markets under Lockdown: Insights from New York." Energy Forum.

Benatia, David, and Étienne Billette de Villemeur. 2019. "Strategic Reneging in Sequential Imperfect Markets." Center for Research in Economics and Statistics Working Paper.

Brewer, Dylan. 2020. "The Economics Costs of Forecasting Errors in the PJM Interconnection Due to the COVID-19 Quarantine." Energy Forum.

Burlig, Fiona, Christopher Knittel, David Rapson, Mar Reguant, and Catherine Wolfram. 2019. "Machine Learning from Schools about Energy Efficiency." NBER Working paper.

Davis, Lucas W. 2017. "Evidence of a decline in electricity use by US households." Economics Bulletin, 37(2): 1098-1105.

EIA. 2019. "Electric Power Monthly June 2019.” Energy Information Agency.

EIA. 2020. "Daily electricity demand in New York falls about $13 \%$ after COVID-19 mitigation efforts." Energy Information Agency. https://www .eia.gov/ todayinenergy/detail.php?id=43635, accessed May 2020.

ERCOT. 2020. "COVID-19 Load impact analysis." ERCOT. http://www.ercot. com/content/wcm/lists/200201/ERCOT_COVID-19_Analysis_FINAL.pdf, accessed May 2020. 
Franses, Philip Hans. 2016. "A note on the mean absolute scaled error." International Journal of Forecasting, 32(1): 20-22.

Ftiti, Zied, Hachmi Ben Ameur, and Wael Louhichi. 2020. "New Outlook for Oil Market in the New Post-Coronavirus World." Energy Forum.

Hortaçsu, Ali, and Steven L. Puller. 2008. "Understanding Strategic Bidding in Multi-Unit Auctions: A Case Study of the Texas Electricity Spot Market." The RAND Journal of Economics, 39(1): 86-114.

IATA. 2020. "COVID-19 Cash Burn Analysis." International Air Transport Association.

IMF. 2020. "World Economic Outlook, April 2020 : The Great Lockdown." International Monetary Fund World Economic and Financial Surveys.

ISONE. 2020. "NEPOOL Participants Committee Report." ISO New England. https://www.iso-ne.com/static-assets/documents/2020/05/ may-2020-coo-report.pdf, accessed May 2020.

Ito, Koichiro, and Mar Reguant. 2016. "Sequential Markets, Market Power, and Arbitrage." American Economic Review, 106(7): 1921-57.

Kissler, Stephen M, Christine Tedijanto, Edward Goldstein, Yonatan H Grad, and Marc Lipsitch. 2020. "Projecting the transmission dynamics of SARSCoV-2 through the postpandemic period." Science, 368(6493): 860-868.

Moore, Kristine, Lipsitch Marc, John Barry, and Michael Osterholm. 2020. "COVID-19: The CIDRAP Viewpoint. PArt 1: The Future of the COID-19 Pandemic: Lessons Learned from Pandemic Influenza." CIDRAP.

Narajewski, Michał, and Florian Ziel. 2020. "Changes in electricity demand pattern in Europe due to COVID-19 shutdowns." Energy Forum.

Newbery, David, Michael G Pollitt, Robert A Ritz, and Wadim Strielkowski. 2018. "Market design for a high-renewables European electricity system." Renewable and Sustainable Energy Reviews, 91: 695-707. 
NYISO. 2020. "COVID-19 and the Electric Grid: Load Shifts as New Yorkers Respond to Crisis." NYISO. https://www.nyiso.com/-/ covid-19-and-the-electric-grid-load-shifts-as-new-yorkers-respond-to-crisis, accessed May 2020.

Ortega-Vazquez, Miguel A., and Daniel S. Kirschen. 2006. "Economic impact assessment of load forecast errors considering the cost of interruptions." 8-pp, IEEE.

Percy, Steve, and Bruce Mountain. 2020. "Covid-19 and Social Distancing: Does It Show Up in the Demand for Electricity?" Energy Forum.

PJM. 2020. "Estimated Impact of COVID-19." PJM. https://www.pjm. com/-/media/committees-groups/subcommittees/las/2020/20200505/ 20200505-item-03-covid-19-impact-update.ashx, accessed May 2020.

Reguant, Mar. 2014. "Complementary Bidding Mechanisms and Startup Costs in Electricity Markets." The Review of Economic Studies, 81(4): 1708-1742.

RTE. 2020. "L'impact de la crise sanitaire sur le fonctionnement du système électrique." Réseau Transport Électricité. https://www.rte-france.com/sites/ default/files/impacts_de_la_crise_sanitaire_covid-19_sur_le_systeme_ electrique.pdf, accessed May 2020.

Tsagkari, Marula. 2020. "Impact of Coronavirus on Distributed Energy Generation with the Application of Demand-Side Management." Energy Forum.

Wolak, Frank A. 2003. "Identification and Estimation of Cost Functions Using Observed Bid Data: An Application to Electricity Markets." Advances in Economics and Econometrics - Theory and Applications, 115-149.

Wolfram, Catherine D. 1999. "Measuring Duopoly power in the British Electricity Spot Market." American Economic Review, 805-826. 